\title{
OPEN Polysaccharide hydrogel based 3D printed tumor models for chemotherapeutic drug screening
}

\author{
Aragaw Gebeyehu ${ }^{1,4}$, Sunil Kumar Surapaneni ${ }^{1,4}$, John Huang ${ }^{2}$, Arindam Mondal ${ }^{1}$, \\ Vivian Ziwen Wang ${ }^{2}$, Nana Fatima Haruna ${ }^{2}$, Arvind Bagde ${ }^{1}$, Peggy Arthur ${ }^{1}$, Shallu Kutlehria ${ }^{1}$, \\ Nil Patel ${ }^{1}$, Arun K. Rishi ${ }^{3}$ \& Mandip Singh ${ }^{1 凶}$
}

A series of stable and ready-to-use bioinks have been developed based on the xeno-free and tunable hydrogel (VitroGel) system. Cell laden scaffold fabrication with optimized polysaccharide-based inks demonstrated that Ink H4 and RGD modified Ink H4-RGD had excellent rheological properties. Both bioinks were printable with 25-40 kPa extrusion pressure, showed $90 \%$ cell viability, shearthinning and rapid shear recovery properties making them feasible for extrusion bioprinting without UV curing or temperature adjustment. Ink H4-RGD showed printability between 20 and $37^{\circ} \mathrm{C}$ and the scaffolds remained stable for 15 days at temperature of $37^{\circ} \mathrm{C}$. 3D printed non-small-cell lung cancer (NSCLC) patient derived xenograft cells (PDCs) showed rapid spheroid growth of size around $500 \mu \mathrm{m}$ in diameter and tumor microenvironment formation within 7 days. $I C_{50}$ values demonstrated higher resistance of 3D spheroids to docetaxel (DTX), doxorubicin (DOX) and erlotinib compared to 2D monolayers of NSCLC-PDX, wild type triple negative breast cancer (MDA-MB-231 WT) and lung adenocarcinoma (HCC-827) cells. Results of flow property, shape fidelity, scaffold stability and biocompatibility of H4-RGD suggest that this hydrogel could be considered for 3D cell bioprinting and also for in-vitro tumor microenvironment development for high throughput screening of various anticancer drugs.

Traditionally, anticancer drugs are evaluated in conventional two-dimensional (2D) cell culture platforms. However, conventional 2D cultured cancer cells cannot mimic the complexity and heterogeneity of in-vivo tumors, which usually grow in a three-dimensional (3D) conformation ${ }^{1-4}$. To overcome this, various 3D cell culture platforms are being currently developed, which can mimic the in-vivo tumor microenvironment as spheroid cells or organoid models. Recent 3D cell culture models narrow the gap between 2D cell culture models and animal disease models by mimicking/recapitulating in-vivo or natural 3D tumor microenvironment. They are also useful in drug discovery for determining the sensitivity of chemotherapeutics to tumor cells both at the cellular and molecular level $\mathrm{e}^{2,5,6}$.

Hydrogel based 3D scaffolds are particularly gaining attention due to their cell encapsulation capability and property of mimicking native extracellular matrix $(\mathrm{ECM})^{7,8}$. Biochemical, mechanical and physical properties of hydrogels determine 3D tumor microenvironment construction in-vitro. Under patho-physiological conditions, tumor cells have the tendency to bisect stromal and connective tissues depending on the ECM stiffness, porosity and linearity. Ideal bioprinted cell-laden scaffolds majorly mimic the stiffness of in-vivo tumor microenvironment ${ }^{9-11}$.

Rheological modifications of the hydrogel can directly influence bioprinting, scaffold shape fidelity, viability and proliferation of cells ${ }^{12-14}$. These also aid in mimicking in-vivo tumor stiffness and native ECM viscoelastic properties. Flow property and tensile strength are the two rheological parameters for bioink extrusion and scaffold formation ${ }^{12,13,15}$. Collagen, fibrin, gelatin, alginate and hyaluronic acid are the widely used natural polymeric biomaterials for bioink formulation because of their resemblance to natural extracellular matrix (ECM)

${ }^{1}$ College of Pharmacy and Pharmaceutical Sciences, Florida A\&M University, Tallahassee, FL 32307, USA. ${ }^{2}$ TheWell Bioscience, North Brunswick, New Jersey 08902, USA. ${ }^{3}$ John D. Dingell VA Medical Center, Karmanos Cancer Institute, Department of Oncology, Wayne State University, Detroit, MI 48201, USA. ${ }^{4}$ These authors contributed equally: Aragaw Gebeyehu and Sunil Kumar Surapaneni. ${ }^{\circledR}$ email: mandip.sachdeva@gmail.com 
components ${ }^{16-18}$. VitroGel is a ready-to-use, xeno-free hydrogel system for $3 \mathrm{D}$ cell culture research. It can be modified with multi-functional ligands and mechanical strength to closely mimic the natural extracellular matrix (ECM) environment to support a wide range of cell types for different applications. The hydrogel is room temperature stable, has a neutral $\mathrm{pH}$, transparent, permeable and compatible with different imaging systems. The solution transforms into a hydrogel matrix by simply mixing with the cell culture medium.

Biocompatibility, hydrophilicity, biomimetic ability, bio-processability, biodegradability, and affordability of the bioinks are also taken into consideration during $3 \mathrm{D}$ printing of cell laden scaffolds ${ }^{16}$. During $3 \mathrm{D}$ printing, less viscous bioinks easily flow through the narrow printing nozzle but they have the drawbacks of smearing and low shape fidelity ${ }^{12,19}$. Highly viscous bioinks can give better shape resolution by using high extrusion pressure ${ }^{16,19}$ but creation of high shear force in the printing nozzle by application of higher extrusion pressure causes cell destruction during printing process ${ }^{16,20}$. So, optimizing the flow properties is the primary criteria of printable bioinks ${ }^{21-23}$.

Polymer crosslinking method is also another key parameter of the bioink for 3D printed scaffolds fabrication $^{24-26}$. Crosslinking by hydrogen bonds, crystallization, ionic interactions and protein interaction are examples of physical crosslinking mechanisms ${ }^{26,27}$. Physically crosslinked bioinks are usually associated with poor mechanical stability. Covalent bonding between polymer and crosslinker functional groups is an example of chemical crosslinking mechanisms ${ }^{28}$. Among various methods, covalent crosslinking is proved to be an effective method for improving the physiological stability of printed structures ${ }^{29,30}$. However, toxicity and unwanted reactions of the crosslinker with the bioactive substances present in the hydrogel matrix limit their application. Changes in $\mathrm{pH}$ and temperature, high energy radiation, free radical polymerizations can be used for crosslinking in $3 \mathrm{D}$ cultures ${ }^{27}$.

In this study, we hypothesize to test a series of room temperature stable and ready-to-use hydrogels by working in collaboration with TheWell Bioscience (North Brunswick, NJ 08902) company. Our goal is to develop a hydrogel which mimics the in-vivo tumor microenvironment, shows good printability, rheological characteristics (i.e., shear-thinning and rapid recovery rheological properties of hydrogels can lead to a stable printed structure after extrusion), biocompatibility and also can be used for application of screening of anti-cancer drugs. As current crosslinking methods of bioinks such as sudden changes in temperature, chemical reactions, and exposure to high energy radiation (UV light) could cause destruction to the cells during the process of solidification of printed scaffold after hydrogel extrusion ${ }^{31,32}$, we would also like to have our printed cell laden scaffolds developed with characterized hydrogel have additional property of getting crosslinked with the cell culture media, maintaining good biocompatibility and stability for long periods of time. Since there are no requirements of crosslinking through temperature changes, chemicals and radiation during bioprinting, this novel bioink could be an easy-to-use system to carry out comparative cytotoxicity testing of various anticancer drugs in 3D printed spheroids and conventional $2 \mathrm{D}$ cultures.

\section{Results}

Bioink optimization for scaffold fabrication and bioink cytocompatibility studies. After testing a series of room temperature stable and ready-to-use hydrogels received from TheWell Bioscience (North Brunswick, NJ 08902), we found that Ink H4 and its modified form, H4-RGD showed high shape fidelity along with high cell viability. Both the hydrogels showed good viability of MDA-MB-231 WT cells after immediate postprinting evaluation by performing Calcein AM/Ethidium homodimer III staining, which showed the images of live (stained green) and dead (stained red) cells (Fig. 1A) and the percentage of cell viability (Fig. 1B) was calculated by NIH ImageJ software. We observed that both these inks were printed under pressure conditions ranging from 25 to $50 \mathrm{kPa}$ (Fig. 1C). We observed poor printability with Ink H1 (Supplementary information; Fig. S1A) but we have seen good viability in printed Ink H1 cell laden scaffolds (Supplementary information; Fig. S2). Ink $\mathrm{H} 2$ showed printability (Supplementary information; Fig. S1B) and good cell viability (Supplementary information; Fig. S2) but the printed scaffolds were not stable for further assays. Although the printability was good with Ink H3 (Supplementary information; Fig. S1C), it used high extrusion pressure (i.e., approximately $180 \mathrm{kPa}$ ) for printing (Supplementary information; Fig. S3). Ink H3 printed scaffolds showed poor cell viability (Supplementary information; Fig. S2). It was observed that extrusion pressure of approximately $60 \mathrm{kPa}$ was used for printing of Ink H5 cell laden scaffolds (Supplementary information; Fig. S3). Ink H5 printed cell laden scaffolds showed $85 \%$ viability (Supplementary information; Fig. S2). Figure 2A shows the photographic image of 10-layer printed scaffold with Ink H4-RGD. The printed scaffolds of Ink H4-RGD displayed designed pore size and good line width without any smearing problems (Fig. 2B,C). Figure 2D shows the fluorescent image of NSCLC-PDX cell laden Ink H4-RGD scaffold stained with calcein. The average Pr (printability) value of 12 Ink H4-RGD scaffolds was 0.96 , which indicates that this ink could be considered for 3D printing of cell laden scaffolds. We also investigated the biocompatibility of Ink H4-RGD in various cancer cells and found that all evaluated cell lines of lung cancer (NSCLC-PDX, H460, HCC-827and A549) and breast cancer (MDA-MB-231WT), and bladder cancer (RT4) cells have showed more than $90 \%$ cell viability after post printing evaluation as analysed by counting the cell viability through NIH ImageJ software (Fig. 3).

Rheological properties of optimized bioprintable inks. We evaluated rheological parameters to assess and determine the feasibility of inks H4 and H4-RGD for extrusion based bioprinting without additional curing process. Rheological assessments revealed that Ink H4 and Ink H4-RGD displayed shear thinning properties i.e., we observed decrease in the viscosity when the shear rate was increased (Fig. $4 \mathrm{~A}, \mathrm{~B}$ ) at $25^{\circ} \mathrm{C}$. This suggests that inks H4 and H4-RGD can be used for extrusion based bioprinting. Further, oscillation temperature sweep test demonstrated that Ink H4-RGD displayed stable elastic modulus across wide temperature ranges i.e., at room temperature and physiological temperature (Fig. 4C). Further, we observed that Inks H4 and H4-RGD showed shear thinning and shear recovery properties at both $25^{\circ} \mathrm{C}$ and $37^{\circ} \mathrm{C}$ (Fig. 5A,B). Further, we assessed 
A
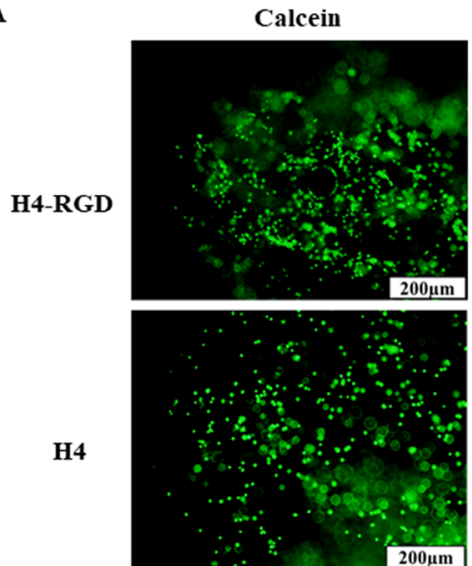

B

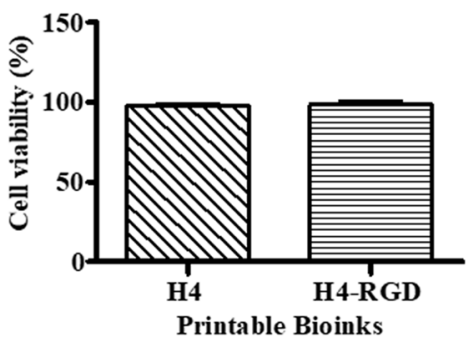

EthD
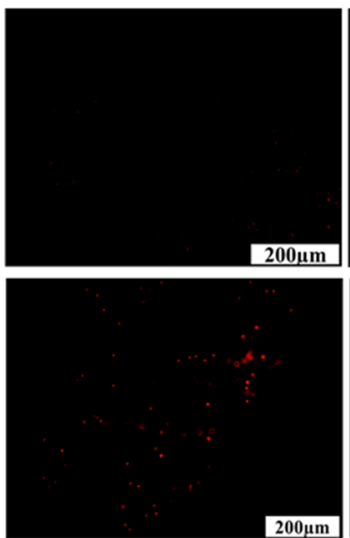
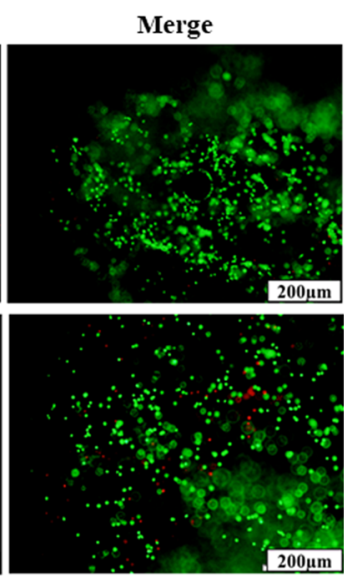

C

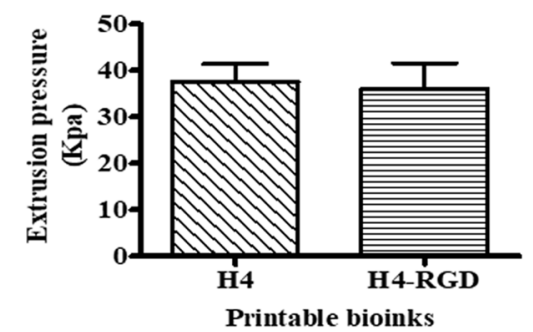

Figure 1. Ink-H4-RGD showing good extrudability and biocompatibility in MDA-MB-231 WT cells. (A) Live/ dead cell assay analysis using Calcein AM/Ethidium homodimer III staining. Results shown were representative of three independent experiments. Microscopic images were acquired and analysed by using Olympus Microscope IX71 and cellSens Standard software (version 1.16; Tokyo, Japan) respectively. (B) Post-printing cell viability of MDA-MB-231 WT cells, which is expressed as percent viability as analysed by NIH ImageJ software (1.43u; https://imagej.nih.gov/ij). (C) Extrusion pressure required for printing of bioinks.

the rheological properties after crosslinking of Ink H4 and H4-RGD with cell culture media in 5:1 ratio. It was observed that crosslinked inks $\mathrm{H} 4$ and H4-RGD also showed shear thinning and shear recovery properties at both $25^{\circ} \mathrm{C}$ and $37^{\circ} \mathrm{C}$ (Fig. 5C,D). However, the recovery rate was faster at $37^{\circ} \mathrm{C}$ in comparison to $25^{\circ} \mathrm{C}$, and also faster with 5:1 mixed (partially crosslinked) samples when compared to unmixed samples (Fig. 5A-D). We observed that all the four samples recovered more than $60 \%$ of the elastic modulus instantly after $500 \%$ shear strain force was ceased, and almost $100 \%$ of the elastic modulus during the 10 min time sweep test, indicating the shear recovery properties of the hydrogel. After the phase 3 test, phase 4 amplitude sweep test was applied to the same samples and we assessed rheological properties. We again observed similar shear-thinning properties of the hydrogel system, further confirming the above results. Since the mechanical strength of the inks can be rapidly recovered after the shearing force was ceased, these inks can maintain the printing structure without further curing process. Inks H4 and H4-RGD have showed pseudoplastic or shear thinning behaviour. The plot of log shear stress vs log shear rate has also showed non-zero intercept. Based on the power law mode equation, we have summarized the flow index (n), flow consistency index (k) and the $\mathrm{R}^{2}$ values of Ink H4 and H4-RGD at $25^{\circ} \mathrm{C}, 37^{\circ} \mathrm{C}$ and $40^{\circ} \mathrm{C}$ in Table 1 . The $\mathrm{n}$ value was found to be less than 1 , which also indicates non-Newtonian pseudoplastic flow properties of Inks H4 and H4-RGD.

Mechanical properties of printable hydrogel and stiffness of cell-laden scaffolds. Based on our printability, cell viability and rheological parameters experimental results, Ink H4-RGD was optimized for 3D printing of cancer cells in-vitro. It was hypothesized that this hydrogel would offer high printability and compressive modulus. Both non crosslinked H4 RGD and partially crosslinked H4-RGD (5:1 of hydrogel and cell culture media) displayed elastic modulus of around $30 \mathrm{kPa}$ after $24 \mathrm{~h}$ incubation with excess cell culture medium at $37^{\circ} \mathrm{C}$ (Fig. 6A). Further, the stiffness of printed NSCLC-PDX cell laden scaffolds was also evaluated by using oscillation-time sweep measurements on day 1,5,10 and 15 (Fig. 6B). The rheological data of cell laden scaffolds showed around $50 \mathrm{kPa}$ elastic modulus and $7 \mathrm{kPa}$ loss modulus during 15 days of incubation. The loss factor was calculated by dividing the average loss modulus with elastic modulus $\left(G^{\prime \prime} / G^{\prime}\right)$. The loss factor of printed cell laden scaffolds was found to be in between 0.14 and 0.4 during 15 days of incubation period (Fig. 6B).

Characterization of 3D spheroids and assessment of in-vitro tumor microenvironment, which mimics the in vivo stromal characteristics. NSCLC-PDX cells were grown in printed scaffolds for 7 days during which the size of spheroids was measured with Olympus IX71 microscope and cellSens Standard software (version 1.16; Tokyo, Japan) after printing on $48 \mathrm{~h}, 72 \mathrm{~h}, 5$ th day and 7 th day. The spheroidal growth and 
A

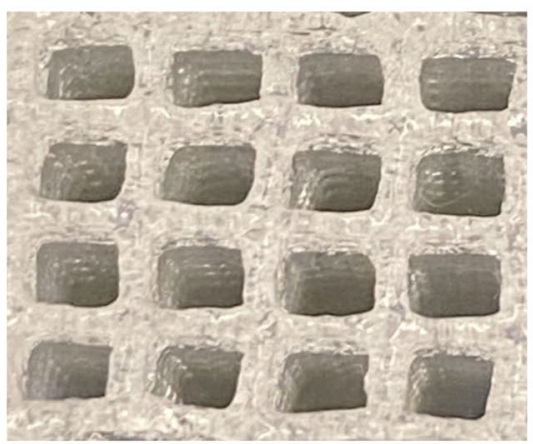

B

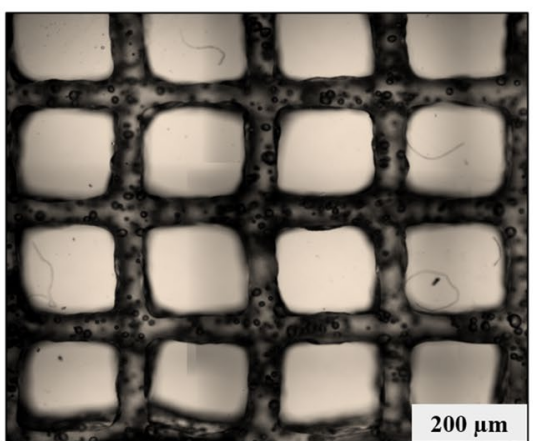

C

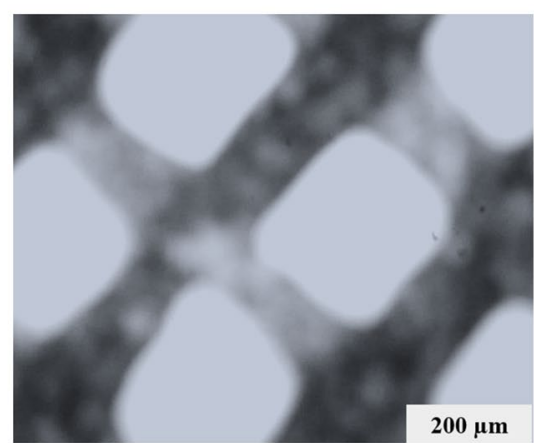

D

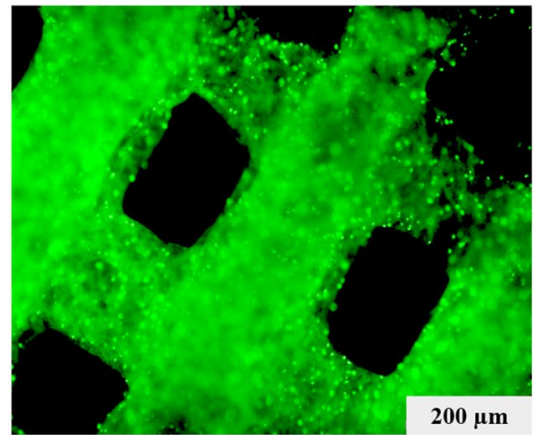

Figure 2. Extrusion uniformity and shape fidelity of printed scaffold. (A) Photographic image of ten layer printed scaffold with Ink H4-RGD. (B, C) Microscopic images showing the pore sizes and line width of printed scaffolds with Ink H4-RGD; (D) Microscopic images showing the cell (NSCLC-PDX) laden Ink H4RGD scaffold after staining with Calcein. Microscopic images were acquired by using Olympus Microscope IX71 and cellSens Standard software (version 1.16; Tokyo, Japan).

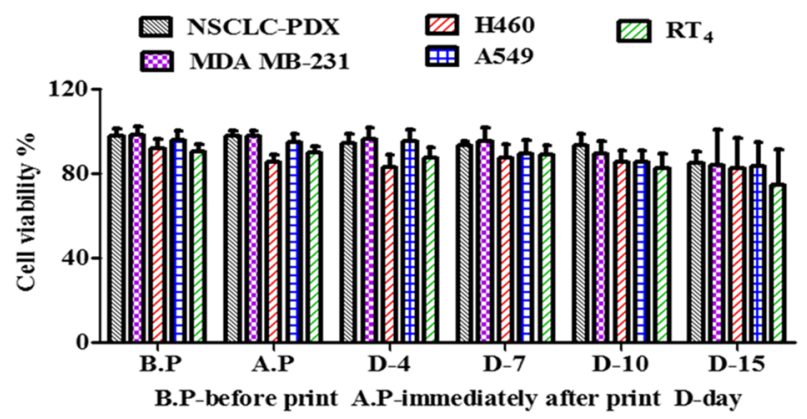

Figure 3. Biocompatibility of Ink H4-RGD. Ink H4-RGD biocompatibility in NSCLC-PDX, RT4, MDA-MB-231, H460 and A549 cell lines before printing, immediately after printing, on Day 4, Day 7, Day 10 and Day 15 by counting cell viability through NIH ImageJ software (1.43u; https://imagej.nih.gov/ij). Results shown were representative of three independent experiments.

the diameter of spheroids was found to be in the range of 100-500 $\mu \mathrm{m}$ during the first 7 days (Fig. 7A). We also characterised 3D spheroids by using SEM, which showed the presence of spheroids inside the printed scaffold of Ink H4-RGD (Fig. 7B). We checked the growth of 3D NSCLC-PDX spheroids by performing NucBlue/Actin green staining for a period of 7 days (Fig. 7C). Figure 8A depicts the image of 3D NSCLC-PDX spheroids with Ink H4-RGD on day 7 after assessed by using NucBlue/Actin green staining. Further, we assessed the presence of tumor microenvironment by performing immunofluorescence assay for E-cadherin and vimentin, which revealed the expression of cell adhesion molecule, E-cadherin and Vimentin in the printed NSCLC-PDX 3D spheroids (Fig. 8B,C).

Comparative 3D and 2D culture platform anticancer drug sensitivity evaluation. We investigated the anti-cancer efficacy of DTX, erlotinib and DOX in the printed 3D cell laden scaffolds formed by using Ink H4-RGD hydrogel and compared their efficacy in 2D monolayers. In all the three tested cell lines (MDA-MB-231WT, NSCLC-PDX and HCC-827), 3D spheroids showed more resistance to DTX, erlotinib and 
Ink H4

A
憩

Ink H4-RGD

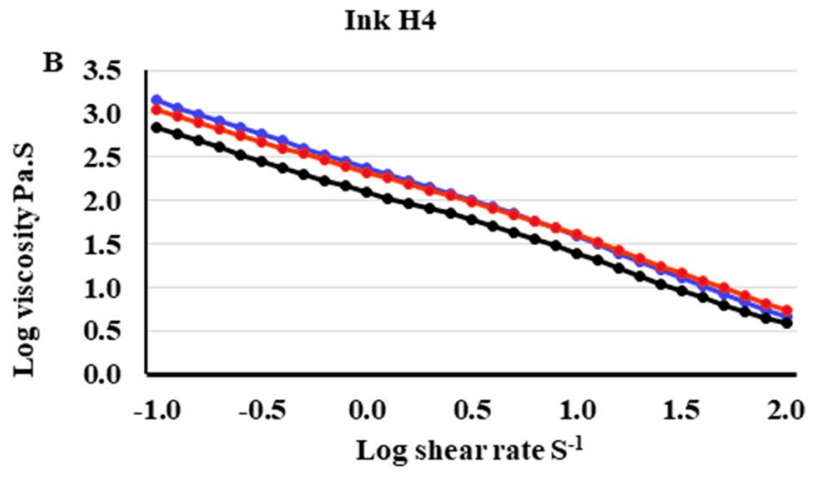

$\rightarrow 25^{\circ} \mathrm{C} \rightarrow 37^{\circ} \mathrm{C} \rightarrow 40^{\circ} \mathrm{C}$

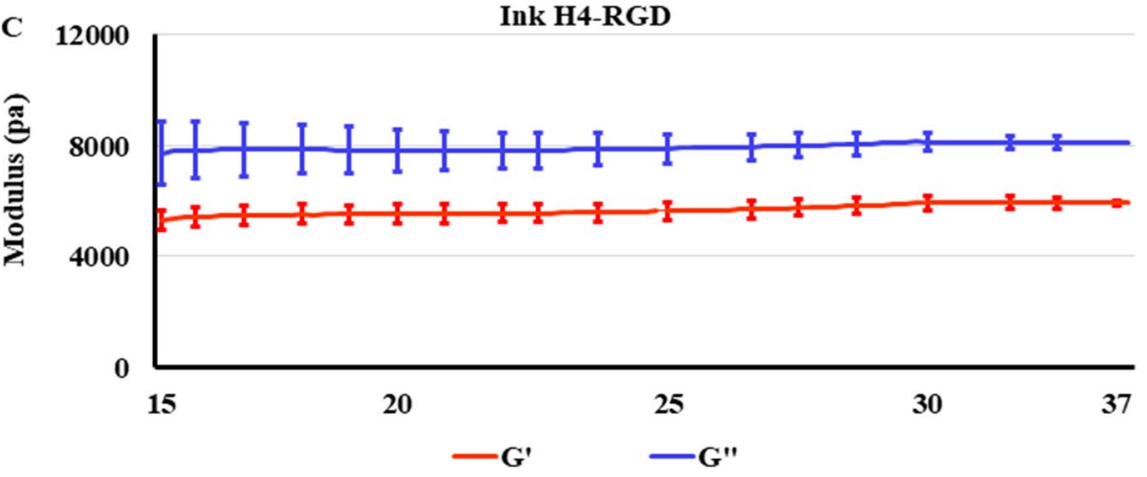

Figure 4. Elastic modulus and viscosity of Ink $\mathrm{H} 4$ and Ink H4-RGD under temperature and time sweep test. (A) The viscosity of Ink $\mathrm{H} 4$ with different shear rates at $25^{\circ} \mathrm{C}, 37^{\circ} \mathrm{C}$ and $40{ }^{\circ} \mathrm{C}$. (B) The viscosity of Ink H4-RGD with different shear rates at $25^{\circ} \mathrm{C}, 37^{\circ} \mathrm{C}$ and $40^{\circ} \mathrm{C}$. (C) Viscoelasticity (modulus) of Ink H4-RGD at different temperatures.

DOX in comparison to $2 \mathrm{D}$ monolayers. The $\mathrm{IC}_{50}$ values for DTX in 2D monolayers of NSCLC PDX, MDAMB-231WT and HCC827 cells were found to be $1.63,1.82$ and $6.83 \mu \mathrm{M}$, respectively and the $\mathrm{IC}_{50}$ values in 3D printed spheroids (NSCLC -PDX, MDA-MB-231WT and HCC-827 cells) were found to be 16.2, 15.1 and $64.5 \mu \mathrm{M}$ respectively (Table 2 ). The $\mathrm{IC}_{50}$ values of erlotinib in 2D monolayer cells of NSCLC-PDX, MDA-MB231WT and HCC-827 were found to be $52.12,52.2$ and $48.53 \mu \mathrm{M}$, respectively. The $\mathrm{IC}_{50}$ values of erlotinib in 3D printed spheroids of NSCLCPDX, MDA-MB-231WT and HCC-827 cells were found to be 152.12, 131.53 and $138.79 \mu \mathrm{M}$ respectively (Table 2). The $\mathrm{IC}_{50}$ values of DOX in 2D monolayer cells of MDA-MB 231WT and HCC 827 were found to be 1.58 and $10.73 \mu \mathrm{M}$ respectively (Table 2). The $\mathrm{IC}_{50}$ values of DOX in $3 \mathrm{D}$ printed spheroids of MDA-MB-231WT and HCC-827 cells were found to be 77.35 and $85.35 \mu \mathrm{M}$, respectively. The $\mathrm{IC}_{50}$ values in $3 \mathrm{D}$ printed cell spheroids ranged from 3 to 90 folds higher than the $2 \mathrm{D}$ counterparts with equivalent cell numbers, all these suggesting that tumor complexity contribute to decreased sensitivity of DTX, erlotinib and DOX in 3D spheroids.

\section{Discussion}

Bioprinting techniques are gaining substantial interest in the field of tissue engineering due to their ability to create complex structures. 3D printing of cell laden scaffolds facilitates homogenous cell/spheroids distribution, homogenous drug diffusion through the entire scaffolds and also opens up new avenues for the fabrication of microtissues ${ }^{33}$. Bioprinting of cells with a designed structure closely mimic in-vivo tissue microenvironment during scaffold-based tissue development ${ }^{34}$. Layer by layer printed scaffolds showed higher cell proliferation and growth when compared to conventional non-printed 3D scaffold cultures ${ }^{35}$. Facilitated media diffusion, easy waste removal and relatively homogenous drug diffusion can be achieved by using 3D bioprinting of cell laden scaffolds with designed pore size and good rheological properties when compared to non-printed 3D cultures ${ }^{36-39}$. Bioprinting can also prevent core necrosis which is the common problem of non-printed polymer-based 3D models ${ }^{40}$. 3D printing has been recently used to develop in-vitro cancer models for chemotherapeutic drug screening ${ }^{41}$. Because of their similarity with the initial avascular growth stage of malignancies, micro-metastases and intra-capillary tumor microregions, 3D spheres of tumor tissue have also been recently explored to investigate and demonstrate the efficacy of various chemotherapeutics ${ }^{42}$.

The imperative step in 3D bioprinting is the formulation of a bioink, which mimics tissue specific intercellular microenvironment ${ }^{43,44}$. In this study, a new formulation of VitroGel RGD-PLUS hydrogel system was used for the first time as a printable bioink for tumor tissue fabrication and in-vitro screening of anticancer drugs. It is an animal origin-free polysaccharide hydrogel system, which is modified with RGD peptide for better cell adhesion. 

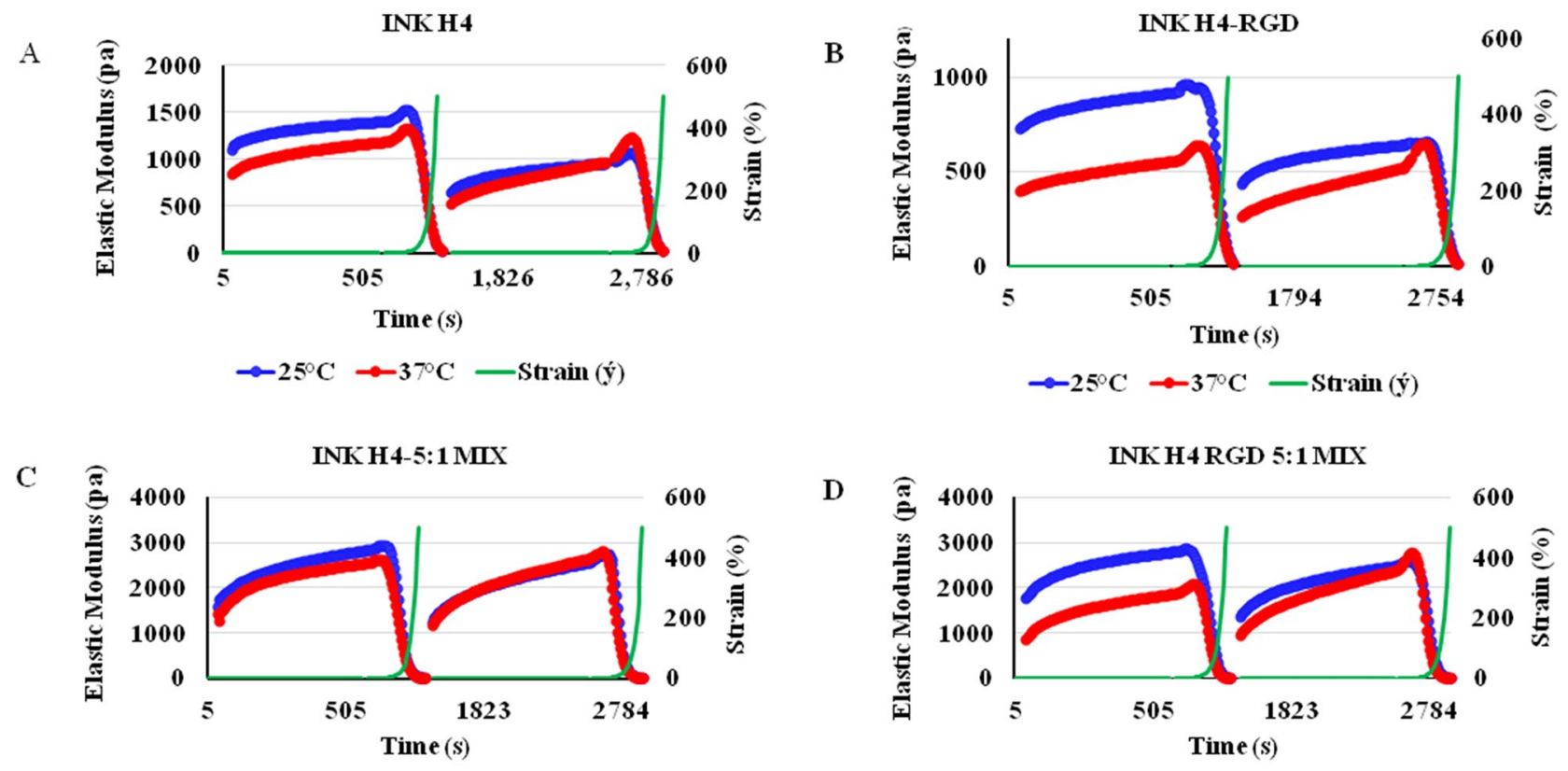

$\rightarrow 25^{\circ} \mathrm{C} \rightarrow 37^{\circ} \mathrm{C} \longrightarrow$ Strain $(\dot{y})$

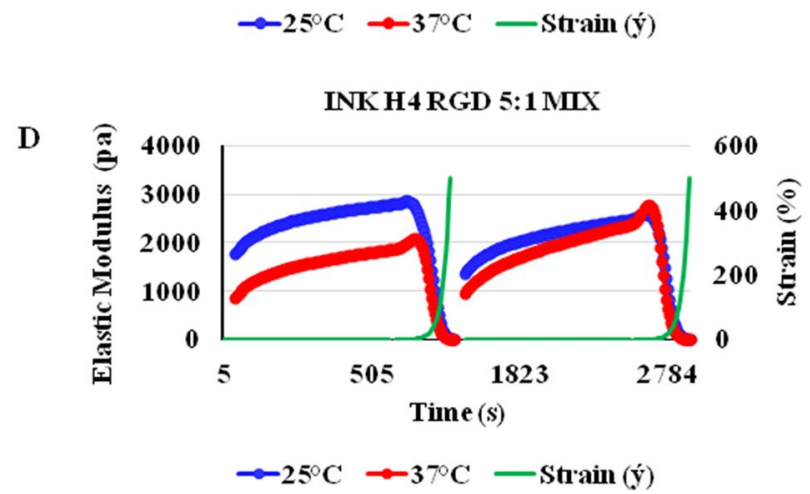

Figure 5. Shear-thinning and rapid shear recovery properties of Ink H4 and Ink H4-RGD by oscillationamplitude sweep test. Two sets of the oscillatory amplitude sweep tests were performed for each bioink (0.1$500 \%$ shear strain, $10 \mathrm{~min}$ each). Oscillation strain above the critical strain disrupts the network of the hydrogel, indicating shear thinning property. The initial $\mathrm{G}^{\prime}$ of the second test indicated the rapid healing of the mechanical property after the first test. (A) Repeated shear-thinning and shear recovery properties of Ink $\mathrm{H} 4$ at both $25^{\circ} \mathrm{C}$ and $37^{\circ} \mathrm{C}$; (B) Repeated shear-thinning and shear recovery properties of Ink H4-RGD at both $25^{\circ} \mathrm{C}$ and $37^{\circ} \mathrm{C}$; (C) Repeated shear-thinning and shear recovery properties of Ink H4 5:1 mix (cross-linked) with cell culture media at both $25^{\circ} \mathrm{C}$ and $37^{\circ} \mathrm{C}$; (D) Repeated shear-thinning and shear recovery properties of Ink H4-RGD 5:1 mix (cross-linked) with cell culture media at both $25^{\circ} \mathrm{C}$ and $37^{\circ} \mathrm{C}$.

\begin{tabular}{|l|l|l|l|l|l|l|}
\hline Hydrogel & \multicolumn{4}{|l|}{ INK-H4 } & \multicolumn{3}{l|}{ INK-H4 RGD } \\
\hline Temperature & $\mathbf{2 5}{ }^{\circ} \mathbf{C}$ & $\mathbf{3 7}^{\circ} \mathbf{C}$ & $\mathbf{4 0}^{\circ} \mathbf{C}$ & $\mathbf{2 5}^{\circ} \mathbf{C}$ & $\mathbf{3 7}{ }^{\circ} \mathbf{C}$ & $\mathbf{4 0}{ }^{\circ} \mathbf{C}$ \\
\hline $\mathrm{n}$ & 0.1252 & 0.1925 & 0.2192 & 0.1251 & 0.2101 & 0.2634 \\
\hline $\mathrm{k}$ & 269.5 & 237.7 & 137.1 & 277.4 & 178.6 & 102.2 \\
\hline $\mathrm{R}^{2}$ & 0.8929 & 0.9511 & 0.969 & 0.9683 & 0.9911 & 0.9922 \\
\hline
\end{tabular}

Table 1. Flow index and consistency index of Inks $\mathrm{H} 4$ and Ink H4-RGD at $25^{\circ} \mathrm{C}, 37^{\circ} \mathrm{C}$ and $40{ }^{\circ} \mathrm{C}$.
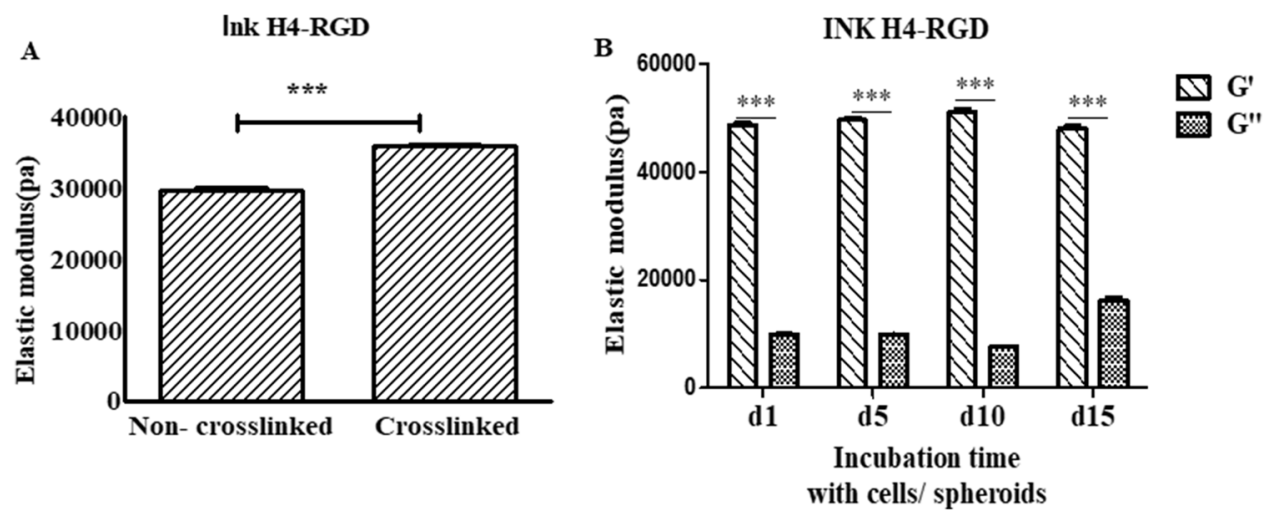

Figure 6. Rheological properties of the hydrogel and stiffness of cell laden scaffolds. (A) Elastic modulus of crosslinked Ink H4-RGD without cells/spheroids. (B) Elastic modulus of cell laden scaffolds when incubated at $37^{\circ} \mathrm{C}$ and $5 \% \mathrm{CO}_{2}$ for 15 days. 
A

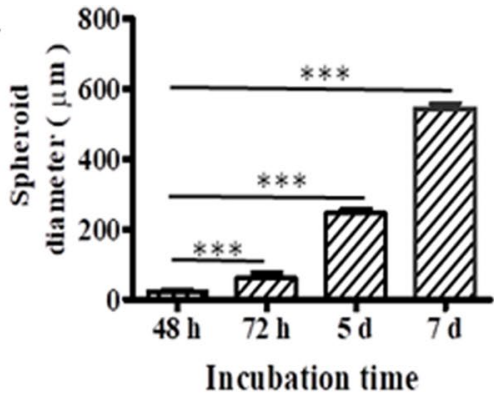

B
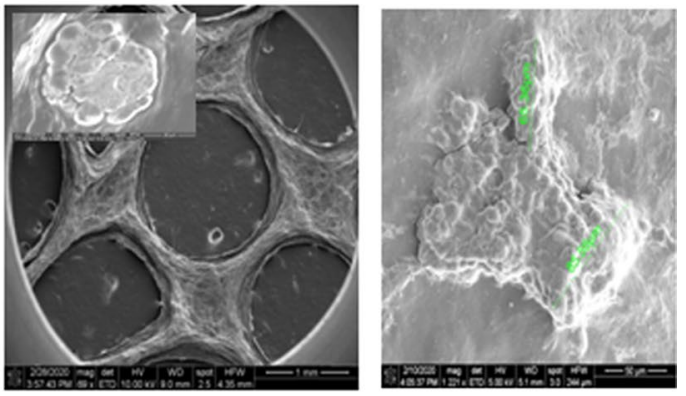

C
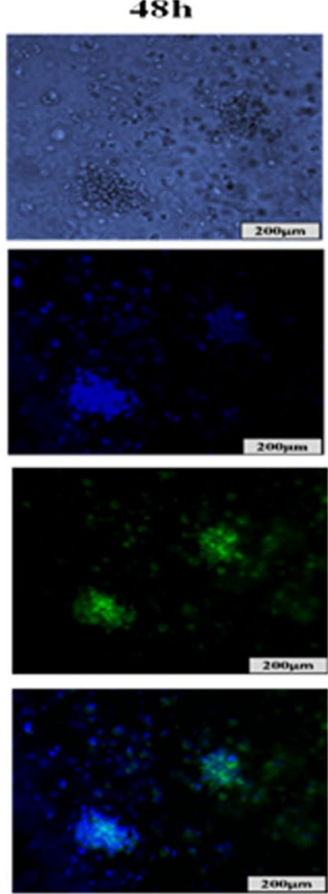

$72 \mathrm{~h}$
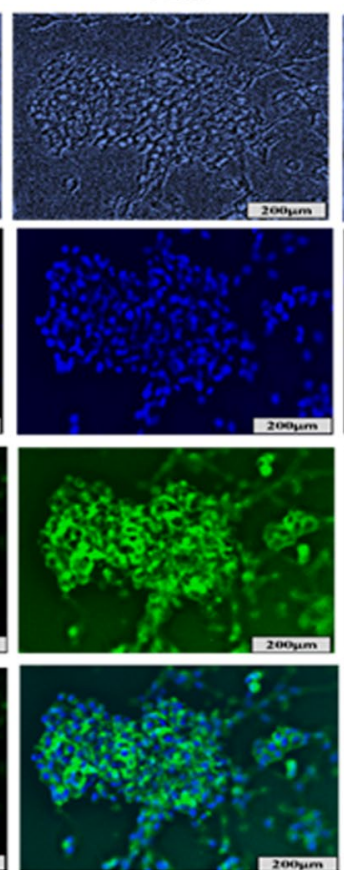

5th day
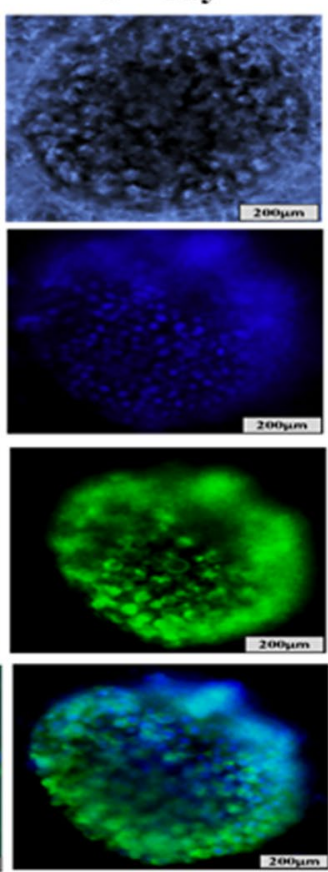

$7^{\text {th }}$ day
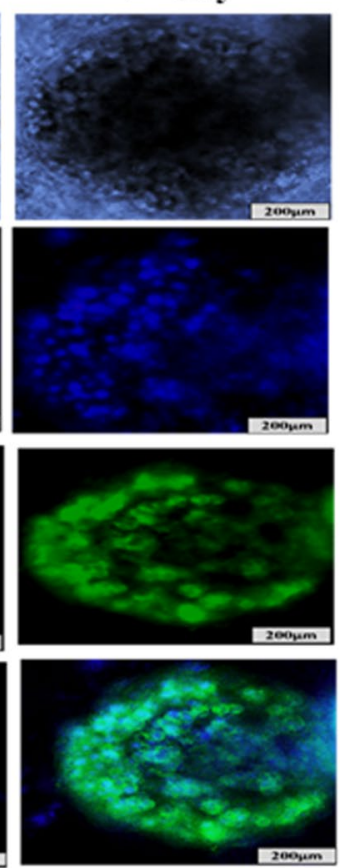

Figure 7. 3D printed NSCLC-PDX cells/spheroids growth in printed ink H4-RGD scaffolds. (A) Average spheroid proliferation/growth rate over a period of 7 days. (B) SEM images of spheroids inside the ink H4RGD scaffold. (C) Spheroid images captured in bright field microscopy and also after staining with NucBlue/Actin Green staining after $48 \mathrm{~h}, 72 \mathrm{~h}$, on 5th day and 7th day. Microscopic images were acquired by using Olympus Microscope IX71 and cellSens Standard software (version 1.16; Tokyo, Japan).

As polysaccharide based bioinks do not have cell attachment motif, they are modified with a tripeptide, ArgGly-Asp (RGD) to improve the adhesion properties ${ }^{45-47}$. During screening of printable bioinks, biocompatibility with cells and medium should be determined before the selection of an ideal bioink ${ }^{48-50}$. This is the first study reporting the use of a carbohydrate based bioink, H4RGD for 3D printing of tumor cells and for screening them against anticancer drugs. Mechanism behind the cross-linking involves the interaction of hydrogel molecules with $\mathrm{Ca}^{2+}$ or $\mathrm{Na}^{+}$from the cell culture medium. This process is slow and forms a soft hydrogel initially. Adding additional cell culture media on top of the hydrogel would allow more ionic molecules to penetrate into the hydrogel matrix, which further saturates the hydrogel cross linking and forms a solid hydrogel.

Bioink extrudability, printed structure line width and scaffold pore size are the determining factors for bioinks evaluation in extrusion-based printings ${ }^{51,52}$. Moreover, bioinks having shear thinning properties can easily pass through the micro-sized nozzle and avoid cell destructive shear forces at the printing nozzle ${ }^{26,53-55}$. Highly viscous bioinks could give better shape resolution but they induce clogging problems at the nozzle tip and can decrease the viability of cells due to the application of high extrusion pressure ${ }^{18,19,26,53,56-59}$. Low viscous bioinks induce smearing and shape demolition problems ${ }^{26}$. In our study, both Ink H4 and Ink H4-RGD have showed shear thinning and shear recovery properties at ambient temperatures between 25 and $37^{\circ} \mathrm{C}$. Moreover, the recovery-time point of both hydrogels to their original elastic modulus $\left(\mathrm{G}^{\prime}\right)$ was observed to be less than one minute after shearing. The shear thinning properties of these inks helped us to print cells with minimum printing pressure, which could also be beneficial for maintaining cell viability. Since the mechanical strength of the ink can be rapidly recovered after the shearing force was ceased, these inks can maintain the printing structure without further curing process. On the other hand, minimum shear duration or rapid recovery properties of the 

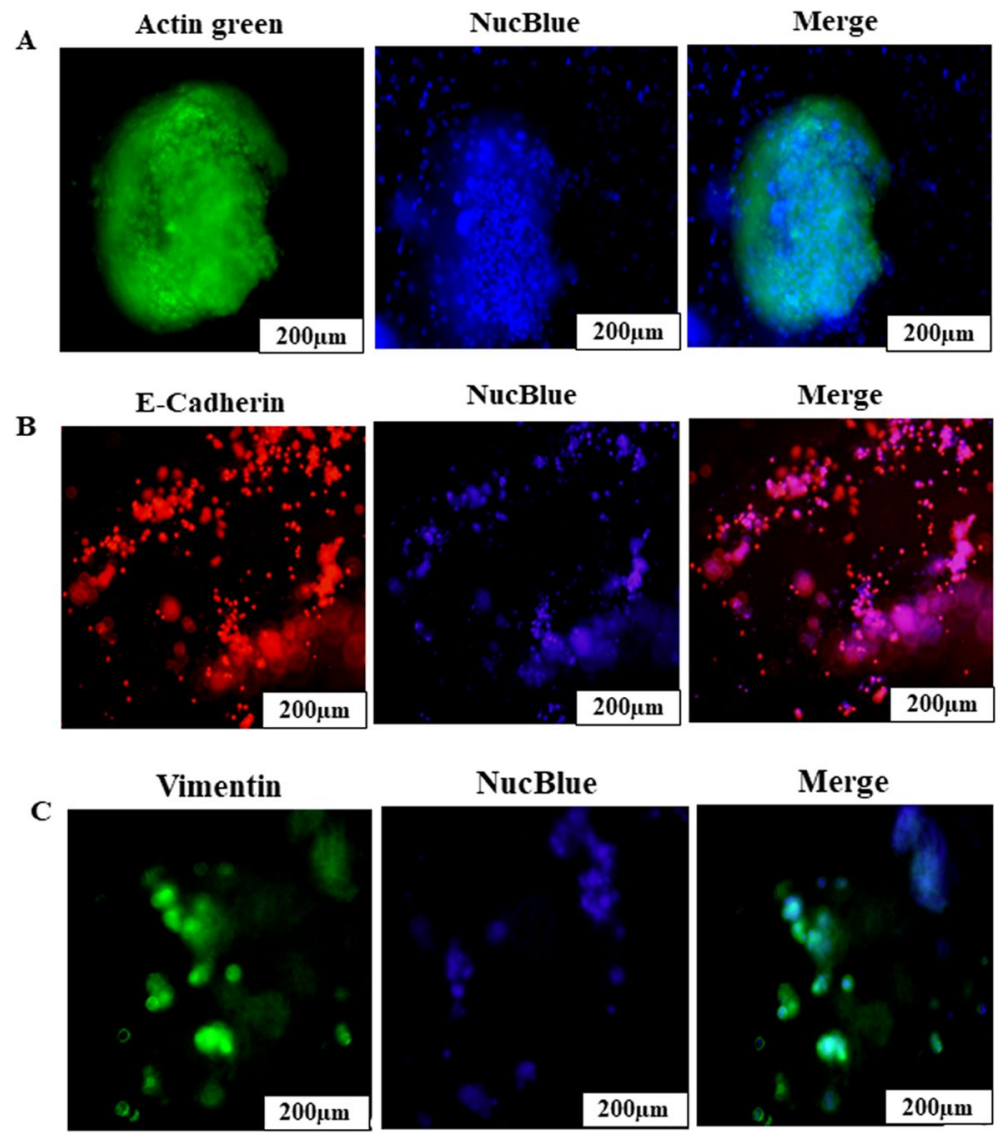

Figure 8. 3D spheroids formation in printed ink H4-RGD NSCLC-PDX cell laden scaffolds. (A) Spheroid formation in NSCLC-PDX cells with ink H4-RGD on the 7th day after staining with NucBlue/Actin Green staining. (B) Immunofluorescence staining for E-cadherin in printed NSCLC-PDX laden scaffold with ink H4-RGD; (C) Immunofluorescence staining for Vimentin in printed NSCLC-PDX laden scaffold with ink H4-RGD. Microscopic images were acquired by using Olympus Microscope IX71 and cellSens Standard software (version 1.16; Tokyo, Japan).

\begin{tabular}{|l|l|l|l|l|l|l|}
\hline \multirow{2}{*}{ Cell lines } & \multicolumn{2}{l|}{ DTX IC $_{\mathbf{5 0}}(\mu \mathrm{M})$} & \multicolumn{2}{l|}{ DOX IC $_{\mathbf{5 0}}(\mu \mathrm{M})$} & \multicolumn{2}{l|}{ Erlotinib $\mathrm{IC}_{\mathbf{5 0}}(\mu \mathrm{M})$} \\
\cline { 2 - 7 } & 2D culture & 3D culture & 2D culture & 3D culture & 2D culture & 3D culture \\
\hline NSCLC-PDX & $1.63 \pm 0.23$ & $16.20 \pm 1.67$ & & & $52.12 \pm 3.22$ & $152.5 \pm 5.67$ \\
\hline MDA-MB-231 WT & $1.82 \pm 0.32$ & $15.10 \pm 2.36$ & $1.58 \pm 0.32$ & $77.35 \pm 2.36$ & $52.50 \pm 5.26$ & $131.53 \pm 2.36$ \\
\hline HCC827 & $6.83 \pm 0.89$ & $64.50 \pm 4.56$ & $10.73 \pm 1.65$ & $85.35 \pm 6.56$ & $48.53 \pm 3.65$ & $138.79 \pm 4.56$ \\
\hline
\end{tabular}

Table 2. Cytotoxicity of DTX, DOX and Erlotinib in 2D monolayers and 3D spheroids of NSCLC-PDX, MDAMB-231 WT, and HCC-827 cells. DOX was not used for NSCLC PDX cells due to its lack of effectiveness against lung cancer. The experimental results were expressed as mean \pm standard deviation.

hydrogel are helpful for optimum shape fidelity during scaffold construction ${ }^{60,61}$. During printing process, a solid physical appearance of hydrogel has to be broken or disrupted by minimum shear stress or printing pressure so as to facilitate easy bioink flow through a narrow nozzle without any jamming problem and also to decrease printing related cellular stress ${ }^{19,60}$.

Due to its rapid shear recovering property, our vitroGel hydrogel system can maintain the printing structure without any smearing problems through immediate curing process. However, optimal stiffness and stability of printed cell laden scaffolds, depend upon the cross-linking methods and elasticity nature of the bioinks ${ }^{36,62}$. Crosslinker concentration and crosslinking time determine the viscosity of the hydrogel system ${ }^{63,64}$. Bioinks of 3D scaffold constructs should have a superior crosslinking method which can maintain good tensile strength of the hydrogels and viability of the cells ${ }^{65}$. Among various methods, covalent crosslinking is proved to be an effective method for improving the physiological stability of printed structures ${ }^{29,30}$. Addition of cell suspension into the bioinks often decreases the viscosity and complicates the evaluation of printability ${ }^{51}$. Kajsa et.al demonstrated 
the usage of nanocellulose-alginate bioink and $90 \mathrm{mM} \mathrm{CaCl}_{2}$ (crosslinker) for cartilage tissue engineering ${ }^{66}$. In our study, usage of Ink H4-RGD bioinks demonstrates an advantage of crosslinking with cell culture medium. Due to this crosslinking method, the printed cell laden scaffolds were maintained in good tensile strength throughout the incubation period.

In our study, all the rheological data was recorded with relevant parameters such as shear rate, shear stress, shear strain torque, normal forces, and angular frequencies. The viscosity and visco-elasticity of bioinks were evaluated before printing. Further, stiffness and structural integrity of cell laden scaffolds were also determined. Ink H4-RGD displayed less degradability and excellent tensile strength for an extended period of time among all the tested bioinks, suggesting it as a suitable bioink. Inks H4 and H4-RGD showed favourable flow properties when extruded at the printing pressure ranging from 25 to $50 \mathrm{kPa}$. The loss factor (tan $\delta$ ) of Ink $\mathrm{H} 4$ and H4-RGD showed suitable viscoelasticity for scaffold fabrication. Our results are supported by an earlier study carried out by Katja et al., which showed that bioinks with viscosity range of $30 \mathrm{mPa}-6 \times 10^{7} \mathrm{mPa}$ are printable by extrusion type printer ${ }^{26}$.

Stiffness of the printed cell laden scaffolds plays a crucial role in structural integrity, cell proliferation and tumor spheroid growth ${ }^{67}$. Meiyu et al. showed that stiffer $(48-53 \mathrm{kpa})$ substrates facilitated the proliferation of BMMSCs when compared to soft substrates ${ }^{68}$. Morphological changes of the cells are observed when encapsulated in hydrogels of different stiffness. Stiffer substrates generally promote cell spreading, whereas soft substrates induce more spherical cell shape ${ }^{69}$. Cavo et al. demonstrated the impact of stiffness of hydrogel on spheroids size and growth ${ }^{70}$. In our study, the stiffness (i.e., $30-55 \mathrm{kPa}$ ) of cell laden scaffolds demonstrate higher spheroidal growth and proliferation. Moreover, the stiffness of the scaffolds did not alter/change throughout the incubation period. Printed scaffolds resolution also depends on printing speed, temperature and nozzle diameter ${ }^{58,71}$. Printing with smaller nozzle diameters gives high shape resolution, but it requires high extrusion pressure, which can cause cellular damage ${ }^{71}$. In our study, ink H4-RGD was printed with different nozzle diameters ranging from 200 to $410 \mu \mathrm{m}$ and higher cell viability was observed at a diameter of $410 \mu \mathrm{m}$.

Lattice design plays an important role in 3D printing of cell laden scaffold constructs, as it helps in mimicking cellular microenvironment ${ }^{48,72-75}$. In 3D printed cell culture models, interconnected porous structure helps for the diffusion of nutrients and waste products ${ }^{75}$. In layer by layer printing, scaffold size and the pore size are the determining factors for their stability ${ }^{76}$. Yong et al. demonstrated that diffusion is superior in $3 \mathrm{D}$ grid pattern when compared to non-porous edges ${ }^{77}$. In our study, the designed scaffolds had three layered grid structure with $10 \times 10 \times 1$ dimension, average line width $(400 \mu \mathrm{m})$ and average inter-scaffold porosity $\left(16 \times 10^{4} \mu \mathrm{m}^{2}\right)$ respectively. This design was favourable for high proliferation of the cells and better nutrients diffusion, which was evident from rapid spheroid formation within seven days of incubation.

$3 \mathrm{D}$ spheroid cultures can mimic the oxygen and nutrient gradients of in-vivo tumors ${ }^{78}$. Previous anticancer drug studies revealed that $3 \mathrm{D}$ spheroids show more chemoresistance in comparison to $2 \mathrm{D}$ cell monolayers ${ }^{79-81}$. Tumor heterogeneity is responsible for superior drug resistance in $3 \mathrm{D}$ spheroids when compared to $2 \mathrm{D}$ culture models, which are devoid of essential tumor microenvironment ${ }^{82,83}$. Poor penetration of drugs through the scaffolds and spheroidal microenvironment barriers are also responsible for superior drug resistance in 3D spheroids ${ }^{84-86}$. Thus, there is a need to develop drugs with better penetrating ability to the most interior sections of tumors. The 3D matrix of hydrogel-based scaffolds closely mimic the physical barriers of ECM present around in-vivo tumors. Decreased diffusion of anti-cancer drugs through the spheroids and hypoxia could also contribute to drug resistance in $3 \mathrm{D}$ cultures ${ }^{87}$. Karlsson et al. demonstrated that $3 \mathrm{D}$ spheroids were more resistant than 2D monolayer colon cancer (HCT-116) cells to anticancer drugs ${ }^{88}$. Paclitaxel, an anti-proliferative drug, which normally acts on dividing cells showed drug resistance in $3 \mathrm{D}$ spheroids due to its reduced effect in the interior spheroidal region, which consists of quiescent cells ${ }^{89}$. Besides, the dynamic intercellular and cell-ECM interactions have a major role in drug resistance in $3 \mathrm{D}$ spheroids ${ }^{3}$.

In our study, we have seeded equivalent number of cells i.e., $5 \times 10^{4}$ cells/scaffold/well and evaluated cytotoxicity with DTX, DOX and erlotinib in 2D and 3D bioprinted cultures of NSCLC-PDX, MDA MB 231 WT and HCC-827 cells. IC50 values were significantly higher in 3D spheroids treated with DTX, erlotinib and DOX when compared to 2D monolayers of NSCLC-PDX, MDA-MB-231WT and HCC-B27 cells. These results support that 3D spheroids show more chemoresistance than conventional 2D platforms to DTX, erlotinib and DOX due to the tumor heterogeneity of $3 \mathrm{D}$ spheroids. Our results corroborate with previous reports which show that 3D cultures of alginate based scaffolds are highly resistant to DTX when compared to 2D monolayers of both A549 and H460 cells i.e., IC C $_{50}$ values of DTX in 3D and 2D monolayers of A549 cells are $118.11 \mu \mathrm{M}$ and $1.94 \mu \mathrm{M}$, respectively and $\mathrm{IC}_{50}$ values of DTX in 3D and 2D monolayers of $\mathrm{H} 460$ cells are $76.27 \mu \mathrm{M}$ and $1.41 \mu \mathrm{M}$, respectively ${ }^{91}$. DOX showed higher resistance in 3D cultures of A549 cells when compared to 2D monolayers i.e., $\mathrm{IC}_{50}$ values of DOX in 3D and $2 \mathrm{D}$ monolayers of $\mathrm{A} 549$ cells are $10.1 \mu \mathrm{M}$ and $1.5 \mu \mathrm{M}$ respectively ${ }^{92}$. A study by Mishra et al., has shown that $\mathrm{IC}_{50}$ values of cyclosaplin and DOX are 5.3 and 5.9-fold higher in $3 \mathrm{D}$ cultures when compared to 2D monolayers of MDA-MB-231 cells ${ }^{93}$. Lovitt et al., has also demonstrated increased $\mathrm{IC}_{50}$ value of DOX from $87 \mathrm{nM}$ in 2D monolayers to $636 \mathrm{nM}$ in 3D cultures of MDA-MB-231 cells ${ }^{90}$. Pickl et al. demonstrated that formation of HER 2 homodimers in 3D cultures is responsible for increased cytotoxic effects with trastuzumab in HER2 positive breast and ovarian cancer cells when compared to trastuzumab effect in 2D cultures $^{94}$. However, we observed that 3D spheroids formed by ink H4-RGD for MDA-MB-231 WT, NSCLCPDX and HCC-827 cells showed more resistance in comparison to $2 \mathrm{D}$ cell monolayers. This possibly suggests the role of tumor microenvironment created by Ink H4-RGD in determining the variability of chemotherapeutics response in 3D spheroids. Decreased diffusion of anti-cancer drugs through the spheroids and hypoxia could also contribute to drug resistance in $3 \mathrm{D}$ cultures ${ }^{87}$. Molecular studies are currently in progress to delineate the possible mechanisms for increased chemotherapeutics resistance in 3D cultures when compared to $2 \mathrm{D}$ cell monolayers. 


\section{Conclusions}

Based on the printability, shape fidelity, rheological parameters, scaffolds morphology, cell viability and rapid spheroid formation, Ink H4-RGD was found to be beneficial in developing tumor scaffolds with in-vivo stromal characteristics. This bioink can be crosslinked with cell culture medium, which facilitates good cell growth and scaffold stability. Ink H4-RGD printed NSCLC PDX cell laden scaffolds showed spheroid formation within 7 days. 3D printed spheroids showed more resistance to DOX, DTX and erlotinib in comparison to 2D monolayers of NSCLC PDX, MDA-MB-231 WT and HCC-827 cells.

\section{Methods}

Cell culture, hydrogels and reagents. NSCLC PDX tumor bearing mice [NOD.Cg-Prkdcscid Il2rgtm1Wjl/SzJ; TM00199 (LG0703F)] were received from Jackson labs, Bar Harbor, ME, USA. The tumors were then excised and grown in cultures using appropriate media conditions. Animals used in experiments were housed according to the regulations set by the American Association for Accreditation of Laboratory Animal Care under conditions of $37^{\circ} \mathrm{C}$ and $60 \%$ humidity. All the experiments performed were priorly reviewed and approved by the Institutional Animal Use and Care Committee of Florida Agricultural and Mechanical University (protocol number: 018-04, Office of Laboratory Animal Welfare Assurance ID number: D16-00350 (A358101). MDA-MB-231 WT, A549, RT4, H460 and HCC-827 cells were also used for the study. Bioinks (Ink-H1, Ink-H2, Ink-H3, Ink H-4, Ink H4-RGD and Ink-H5) were received from TheWell Bioscience (North Brunswick, NJ 08902) company. These were formulated based on company's tunable bioink system with different final concentrations such as Ink-H4 (VitroINK 3D) and Ink-H4-RGD (VitroINK RGD) of standard 1X concentration; Ink-H1, Ink-H2 and Ink-H3 of $0.2 \mathrm{X}, 0.5 \mathrm{X}$ and $2 \mathrm{X}$ concentration respectively and Ink-H5 of $0.75 \mathrm{X}$ concentration. The components of ink $\mathrm{H} 4$ and ink H4-RGD are proprietary information as they are being sold by TheWell Bioscience (North Brunswick, NJ 08902) company. To the best of our knowledge according to the information disclosed by The Well Bioscience (North Brunswick, NJ 08902) company, we only know that these inks simulate the natural extracellular matrix (ECM) environment by providing in-vitro anchorage and homing sites for in-vitro cells and spheroids. This polysaccharide-based hydrogel system (VitroGel) has also shielding and nurturing property, which closely mimics the in-vivo ECM. In comparison to the reported bioinks, Inks $\mathrm{H} 4$ and H4-RGD can be printed through extrusion due to their special shear-thinning and rapid recovery rheological properties of the hydrogel system and also can maintain the printed structure without further UV crosslinking. Moreover, these Inks H4 and H4-RGD can be mixed with different growth factors or compounds if needed to support different cell culture applications. DMEM/F12 media was purchased from Genesee Scientific (SanDiego, CA, USA). RPMI media, bFGF and EGF were purchased from Sigma-Aldrich (St. Louis, MO, USA). B27 supplement, NucBlue, Actin-Green reagents were purchased from Life technologies (USA). Live-Dead cell assay reagent was purchased from Biotium Inc (USA). E-cadherin and vimentin antibodies was purchased from Cell Signaling Technology (USA). Antirabbit, anti-mouse FITC and Rh conjugated secondary antibodies were purchased from Santa Cruz Biotechnology (USA). BIO-X and INKREDIBLE 3D bioprinter (CELLINK Inc, Sweden) were used to print all inks.

Bioink optimization for scaffold fabrication. Ink H4 and H4-RGD were used for printability evaluation. Both these inks were prepared by our collaborator (The Well Bioscience Company). Based on the preliminary studies of VitroGel hydrogel systems, we observed that these formulated bioinks were found to be crosslinkable with cell culture medium. The experiment was designed to test printability of Ink H4 and H4-RGD, to determine crosslinker ratio (hydrogel:cell culture medium), crosslinking time, and also to evaluate printed scaffolds. For crosslinking and gelation study, each sample was diluted with a cell culture medium in the ratio (hydrogel to cell culture medium respectively) of 1:1, 1:2, 1:3, 1:4, 1:5, 2:1, 3:1, 4:1, 5:1, 6:1 and 10:1. For printability test, hydrogels were loaded into $3 \mathrm{~mL}$ printing cartridges and then connected to a controllable pressure regulator $(0-1000 \mathrm{k} \mathrm{pa})$ on a Bio-X printer. Three-layered $(10 \times 10 \times 1 \mathrm{~mm})$ scaffolds were printed on a petri-dish using $22 \mathrm{G}$ nozzle ( $410 \mu \mathrm{m}$ diameter) and the printability was evaluated in terms of shape fidelity, applied extrusion pressure and post-printing cell viability. The line width and pore size of all the scaffolds were measured using Olympus IX71 microscope and cellSens Standard software (version 1.16; Tokyo, Japan).

The printability (Pr) of Ink H4 and Ink H4-RGD were defined based on the square shape using the following mathematical function

$$
\operatorname{Pr}=\Pi / 4 \times 1 / \mathrm{C}=\mathrm{L}^{2} / 16 \mathrm{~A}
$$

where A, C and L symbols indicate pore area, pore circularity and perimeter of the printed scaffold pore. Under ideal conditions, the printed lines of the constructs would be of square shape, and the Pr value was equal to 1 . Larger Pr value indicates the greater gelation degree of the bioink and vice versa. For determining the Pr value of each print scaffold, perimeter and area of interconnected channels $(n=12)$, optical images of printed constructs were analyzed in Olympus IX71 microscope and cellSens Standard software (version 1.16; Tokyo, Japan).

Cell printing and bioink cytocompatibility. Ink-H4 RGD was chosen for further biocompatibility evaluation studies. NSCLC-PDX, MDAMB-231 WT, A549, H460, HCC-827 and bladder cell (RT4) were used for biocompatibility evaluation of Ink H4 RGD. For each cell line, $400 \mu \mathrm{L}$ of cell suspension $\left(5 \times 10^{6}\right.$ cells $)$ was mixed homogenously in $2 \mathrm{~mL}$ of H4-RGD bioink by a sterile spatula and loaded carefully into the printing cartridge. Conical shape $22 \mathrm{G}$ nozzle was used for printing all cell lines throughout the biocompatibility experiments. The final printed cell laden scaffolds had $10 \times 10 \times 1 \mathrm{~mm}$ dimensions with an estimation of 50,000 cells per each scaffold. All printing procedures were carried out at room temperature in 12 well plates and each cell-laden 
scaffold was covered with $500 \mu \mathrm{L}$ organoid culture medium and then incubated at $37^{\circ} \mathrm{C}$ and $5 \% \mathrm{CO}_{2}$. Organoid cell culture medium was prepared from DMEM F-12/and RPMI with EGF (Epidermal growth factor), bFGF (basic fibroblast growth factor) and B-27 complement. The cell viability was evaluated before printing (simple gel cell mix) and after printing on day (immediately), 2, 4, 7 and 10 by using a live and dead cell assay kit. Briefly, printed cells were stained with $2 \mu \mathrm{M}$ calcein-AM/4 $\mu \mathrm{M}$ EthD-III for $1 \mathrm{~h}$ and washed twice with serum free media. Thereafter, the images were acquired and analysed by using Olympus IX71 microscope and cellSens Standard software (version 1.16; Tokyo, Japan) respectively. Relative percentage of live and dead cells were determined by counting the cells using NIH ImageJ software (1.43u; https://imagej.nih.gov/ij).

Rheological properties of Ink H4 and H4-RGD. Malvern Kinexus Pro + dynamic rheometer (Malvern Panalytical, UK) with a $20 \mathrm{~mm}$ parallel plate of rough surface geometry was used for the evaluation of rheological properties of cell free hydrogels. The viscoelasticity and viscosity of the bionks were evaluated with oscillation-time sweep, flow-sweep, oscillation-temperature ramp and repeated amplitude sweep procedures. Briefly for rheology studies, samples were prepared by two methods, which includes (1) hydrogel without crosslinker (i.e., without cell culture medium) and (2) hydrogel with crosslinker (i.e., with DMEM-F12 medium) at 5:1 ratio. For each measurement, about $200 \mu \mathrm{L}$ sample was used with a measuring gap of $0.5 \mathrm{~mm}$ and the edge of the sample was covered with ultra-low viscosity silicone fluid (viscosity of $5 \mathrm{cSt}$ at $25^{\circ} \mathrm{C}$, Clearco, USA) to prevent sample drying. For samples with cell culture media, $200 \mu \mathrm{L}$ hydrogel (H4 and H4-RGD) was mixed with $40 \mu \mathrm{L}$ of DMEM-F12 medium. The viscosity was evaluated at shear rates ranging from 0.1 to $100 / \mathrm{S}$ at $25^{\circ} \mathrm{C}$. The oscillation temperature ramp evaluation was carried out from 20 to $40^{\circ} \mathrm{C}$ with $2{ }^{\circ} \mathrm{C} / \mathrm{min}$ ramp and $1 \mathrm{~Hz}$.

The shear thinning and recovery properties of the hydrogel were evaluated with repeated time-sweep and amplitude-sweep testing procedures at $25^{\circ} \mathrm{C}$ and $37^{\circ} \mathrm{C}$. Briefly, the hydrogel sample was loaded on the bottom plate of the rheometer and tested under $0.1 \%$ shear strain for 10 min. First testing stage revealed the stability of the hydrogel and its ability to extrude easily. After first stage, an amplitude sweep was applied by increasing the shear strain from 0.1 to $500 \%$ within $4 \mathrm{~min}$. This second stage mimicked the extrusion process, which makes hydrogel flow due to decrease in the elastic modulus when the shear strain was increased. Right after the amplitude sweep, the second time sweep test was immediately applied to evaluate the rapid recovery of the elastic modulus of the hydrogel after printing. The shear stress vs shear rate graph was represented on log-log plot and then the intercept and $\mathrm{R}^{2}$ values were determined. The following adjustable parameters and terms; $\tau$ (shear stress), $\gamma$ (shear rate), $\mathrm{K}$ (consistency index; gives an idea of the viscosity) and $\mathrm{n}$ (flow behaviour index; dimension less) were analysed by simple power law model i.e., $\tau=k \gamma^{n}$, where $\mathrm{n}<1$ denotes pseudoplastic and $\mathrm{n}>1$ indicates dilatants flow.

To test the rheology of fully crosslinked hydrogel, about $1.2 \mathrm{~mL}$ hydrogel from either non crosslinked or partial crosslinked hydrogels (5:1 mix) was added to a $35 \mathrm{~mm}$ petri dish and then covered with $2 \mathrm{~mL}$ DMEMF12 medium. The samples were incubated for $24 \mathrm{~h}$ and the rheology was evaluated with oscillation-time sweep procedure at $37^{\circ} \mathrm{C}$.

Stiffness and stability of printed cell laden scaffolds. The rheology of cell laden scaffolds was assessed using AR 1500Ex Rheometer (TA instrument, USA) with parallel-plate geometry (20 mm, taper angle of $\mathrm{a}=0.0412$ and $\mathrm{rad}=2.36$ ). Briefly, cells were printed with designed scaffolds of $20 \mathrm{~mm}$ diameter, $1 \mathrm{~mm}$ height and $45 \%$ infill density and were incubated in six well plates supplemented with DMEM-F12 organoid media at $37^{\circ} \mathrm{C}$ and $5 \% \mathrm{CO}_{2}$. Oscillation time sweep with a strain of $1 \%$ and angular frequency of $10 \mathrm{rad} / \mathrm{s}$ was used for cell laden stiffness evaluation and the stiffness was measured during day 1, 5, 10 and 15. Each cell laden scaffold was constructed from Ink H4-RGD with NSCLC-PDX cells $\left(2 \times 10^{5}\right.$ cells per scaffold $)$.

Characterisation of 3D spheroids by using NucBlue and actin green assay. Nucleus and Actin staining (NucBlue and Actin green assay) were performed to confirm the spheroids formation and their growth in the printed scaffolds. The media was removed from the scaffolds and then the scaffolds were subjected to fixation by using $4 \%$ formaldehyde for $1 \mathrm{~h}$ at room temperature and washed with $1 \mathrm{~mL}$ of HBSS (twice). The scaffolds were then permeabilized with $0.1 \%$ Triton X-100 and subsequently after washing with HBSS, staining with NucBlue and ActinGreen 488 (Life Technologies) was performed according to the manufacturer's protocol. The assay was performed after $48 \mathrm{~h}, 72 \mathrm{~h}$, on 5 th day and 7 th day. Images were then acquired by using Olympus IX71 microscope and cellSens Standard software (version 1.16; Tokyo, Japan).

Scanning electron microscopy (SEM) analysis of the spheroid structure. NSCLC-PDX spheroids (on the 10th day) were fixed with $4 \%$ glutaraldehyde for $30 \mathrm{~min}$. Fixed spheroids were subsequently dehydrated with graded proportions of ethanol $(25,50,75,95$, and $100 \%)$. Afterwards, complete dried scaffolds were coated with palladium gold, and finally examined under a scanning electron microscope (JEOL) at an acceleration voltage of $5 \mathrm{kV}$.

Immunofluorescence staining of 3D spheroids for assessment of in vitro tumor microenvironment, which mimics the in vivo stromal characteristics. On the 7th day, printed cell-laden scaffolds (i.e., NSCLC PDX spheroids) were fixed with $4 \%$ formaldehyde for $30 \mathrm{~min}$ at $37^{\circ} \mathrm{C}$, washed thrice with PBST and permeabilized with $0.4 \%$ Triton for $30 \mathrm{~min}$. The triton washed out and blocked with 5\% BSA overnight, washed thrice with PBST and incubated with E-Cadherin-rabbit and Vimentin-rabbit overnight. Then the scaffolds were washed thrice with PBST and further stained with the secondary antibodies for $3 \mathrm{~h}$. Finally, the scaffolds were washed thrice with PBST and stained with NucBlue for $30 \mathrm{~min}$. Images were taken with Olympus IX71 microscope. 
Cytotoxicity assays. For cytotoxicity study, $4 \mathrm{~mL}$ of Ink H4-RGD was mixed uniformly with $800 \mu \mathrm{L}$ cell suspension (containing $1.2 \times 106$ cells), loaded into the printing cartridge and then printed onto the 24 well plates with estimated cell density of $5 \times 10^{4}$ cells/scaffold. Each printed cell-laden scaffold was nourished with $250 \mu \mathrm{L}$ of organoid medium every other day and incubated at $5 \% \mathrm{CO}_{2}$ and $37^{\circ} \mathrm{C}$. On day 5 , the cell-laden scaffolds (with MDAMB-231 WT, NSCLC-PDX and HCC 827 cells) were treated with anticancer drugs erlotinib, DTX and DOX. DOX was not usually used against lung cancer and hence was not used for NSCLC-PDX). After $48 \mathrm{~h}$ incubation, the scaffolds were stained with $300 \mu \mathrm{L}$ of MTT $(0.05 \mathrm{mg} / \mathrm{mL})$ for $4 \mathrm{~h}$ and the formazan crystals were dissolved with $250 \mu \mathrm{L}$ of DMSO for $2 \mathrm{~h}$. For comparison, conventional 2D cell culture models with equal cell density were also prepared for each cell line. Briefly, $5 \times 10^{4}$ cells were plated in 24 well plates and incubated at $37^{\circ} \mathrm{C}$ and $5 \% \mathrm{CO}_{2}$ for $48 \mathrm{~h}$. After $48 \mathrm{~h}$, all the cells were treated with similar drugs (Erlotinib, DTX and DOX) separately. Then, MTT solution $(0.05 \mathrm{mg} / \mathrm{mL})$ was added for 3-4 h. Finally, the formazan crystals were dissolved with $250 \mu \mathrm{L}$ of DMSO for $30 \mathrm{~min}$. The absorbance was measured at a wavelength of $565 \mathrm{~nm}$ on a Fluoroskan Ascent FLTM instrument (Labsystem). Cytotoxic activity was expressed as the drug concentration that inhibited cell viability by $50 \%\left(\mathrm{IC}_{50}\right)$.

Statistical analysis. The experimental results were expressed as mean \pm standard deviation. Statistical analyses between different groups were performed by one-way ANOVA. p value $<0.05$ was considered as statistically significant.

\section{Data availability}

All the data generated or analyzed during this study are included in this published article (and its "Supplementary Information" files).

Received: 24 March 2020; Accepted: 2 December 2020

Published online: 11 January 2021

\section{References}

1. Lv, D., Hu, Z., Lu, L., Lu, H. \& Xu, X. Three-dimensional cell culture: A powerful tool in tumor research and drug discovery. Oncol. Lett. 14, 6999-7010. https://doi.org/10.3892/ol.2017.7134 (2017).

2. Edmondson, R., Broglie, J. J., Adcock, A. F. \& Yang, L. Three-dimensional cell culture systems and their applications in drug discovery and cell-based biosensors. Assay Drug Dev. Technol. 12, 207-218. https://doi.org/10.1089/adt.2014.573 (2014).

3. Theodoraki, M. A. et al. Spontaneously-forming spheroids as an in vitro cancer cell model for anticancer drug screening. Oncotarget. 6, 21255-21267. https://doi.org/10.18632/oncotarget.4013 (2015).

4. Michor, F. \& Weaver, V. M. Understanding tissue context influences on intratumour heterogeneity. Nat. Cell. Biol. 16, 301-302. https://doi.org/10.1038/ncb2942 (2014).

5. Mirbagheri, M. et al. Advanced cell culture platforms: A growing quest for emulating natural tissues. Mater. Horiz. 6, 45-71 (2019).

6. Kimlin, L. C., Casagrande, G. \& Virador, V. M. In vitro three-dimensional (3D) models in cancer research: An update. Mol. Carcinog. 52, 167-182. https://doi.org/10.1002/mc.21844 (2013).

7. Oliveira, J. M. et al. Hydrogel-based scaffolds to support intrathecal stem cell transplantation as a gateway to the spinal cord: Clinical needs, biomaterials, and imaging technologies. NPJ Regen. Med. 3, 8. https://doi.org/10.1038/s41536-018-0046-3 (2018).

8. Van Vlierberghe, S., Dubruel, P. \& Schacht, E. Biopolymer-based hydrogels as scaffolds for tissue engineering applications: A review. Biomacromol 12, 1387-1408 (2011).

9. Zhang, Y. S. et al. Bioprinting the cancer microenvironment. ACS Biomater. Sci. Eng. 2, 1710-1721 (2016).

10. Asghar, W. et al. Engineering cancer microenvironments for in vitro 3-D tumor models. Mater. Today. 18, 539-553 (2015).

11. Liu, Z. \& Vunjak-Novakovic, G. Modeling tumor microenvironments using custom-designed biomaterial scaffolds. Curr. Opin. Chem. Eng. 11, 94-105 (2016).

12. Kyle, S., Jessop, Z. M., Al-Sabah, A. \& Whitaker, I. S. 'Printability” of candidate biomaterials for extrusion based 3D printing: State-of-the-art'. Adv. Healthc. Mater. 6, 1700264. https://doi.org/10.1002/adhm.201700264 (2017).

13. Ouyang, L., Yao, R., Zhao, Y. \& Sun, W. Effect of bioink properties on printability and cell viability for 3D bioplotting of embryonic stem cells. Biofabrication. 8, 035020 (2016).

14. Liu, Z., Zhang, M., Bhandari, B. \& Yang, C. Impact of rheological properties of mashed potatoes on 3D printing. J. Food Eng. 220, 76-82 (2018).

15. Tian, K. et al. 3D printing of transparent and conductive heterogeneous hydrogel-elastomer systems. Adv. Mater. $29,1604827$. https://doi.org/10.1002/adma.201604827 (2017).

16. Gopinathan, J. \& Noh, I. Recent trends in bioinks for 3D printing. Biomater. Res. 22, 11. https://doi.org/10.1186/s40824-018-0122-1 (2018).

17. Song, R. et al. Current development of biodegradable polymeric materials for biomedical applications. Drug Des. Devel. Ther. 12, 3117. https://doi.org/10.2147/DDDT.S165440 (2018).

18. Zhang, B. et al. 3D Bioprinting: A novel avenue for manufacturing tissues and organs. Engineering. 5, 777-794 (2019).

19. He, Y. et al. Research on the printability of hydrogels in 3D bioprinting. Sci. Rep. 6, 29977. https://doi.org/10.1038/srep29977 (2016).

20. Chang, R., Nam, J. \& Sun, W. Effects of dispensing pressure and nozzle diameter on cell survival from solid freeform fabricationbased direct cell writing. Tissue Eng. Part A 14, 41-48 (2008).

21. Jia, W. et al. Direct 3D bioprinting of perfusable vascular constructs using a blend bioink. Biomaterials 106, 58-68 (2016).

22. Müller, M., Becher, J., Schnabelrauch, M. \& Zenobi-Wong, M. Nanostructured pluronic hydrogels as bioinks for 3D bioprinting. Biofabrication. 7, 035006. https://doi.org/10.1088/1758-5090/7/3/035006 (2015).

23. Gao, T. et al. Optimization of gelatin-alginate composite bioink printability using rheological parameters: A systematic approach. Biofabrication. 10, 034106. https://doi.org/10.1088/1758-5090/aacdc7 (2018).

24. Freeman, F. E. \& Kelly, D. J. Tuning alginate bioink stiffness and composition for controlled growth factor delivery and to spatially direct MSC fate within bioprinted tissues. Sci. Rep. 7, 17042. https://doi.org/10.1038/s41598-017-17286-1 (2017).

25. Petta, D. et al. 3D bioprinting of a hyaluronan bioink through enzymatic-and visible light-crosslinking. Biofabrication. 10, 044104. https://doi.org/10.1088/1758-5090/aadf58 (2018).

26. Hölzl, K. et al. Bioink properties before, during and after 3D bioprinting. Biofabrication. 8, 032002. https://doi.org/10.1088/17585090/8/3/032002 (2016)

27. Akhtar, M. F., Hanif, M. \& Ranjha, N. M. Methods of synthesis of hydrogels. A review. Saudi Pharm. J. 24, 554-559 (2016). 
28. De Azeredo, H., Rosa, M., De Sá, M., Filho, M. S. \& Waldron, K. The use of biomass for packaging films and coatings. In Advances in Biorefineries: Biomass and Waste Supply Chain Exploitation. Woodhead Publishing, 819-874. https://doi.org/10.1533/97808 57097385.2.819 (2014)

29. Wang, L., Shansky, J., Borselli, C., Mooney, D. \& Vandenburgh, H. Design and fabrication of a biodegradable, covalently crosslinked shape-memory alginate scaffold for cell and growth factor delivery. Tissue Eng. Part A 18, 2000-2007 (2012).

30. Ouyang, L., Highley, C. B., Rodell, C. B., Sun, W. \& Burdick, J. A. 3D printing of shear-thinning hyaluronic acid hydrogels with secondary cross-linking. ACS Biomater. Sci. Eng. 2, 1743-1751 (2016).

31. Caliari, S. R. \& Burdick, J. A. A practical guide to hydrogels for cell culture. Nat. Methods. 13, 405-414 (2016).

32. Mansur, H. S., Costa, E. D. S. Jr., Mansur, A. A. \& Barbosa-Stancioli, E. F. Cytocompatibility evaluation in cell-culture systems of chemically crosslinked chitosan/PVA hydrogels. Mater. Sci. Eng. C. 29, 1574-1583 (2009).

33. Rider, P., Kačarević, ŽP., Alkildani, S., Retnasingh, S. \& Barbeck, M. Bioprinting of tissue engineering scaffolds. J. Tissue Eng. 9, 2041731418802090. https://doi.org/10.1177/2041731418802090 (2018).

34. Datta, P., Dey, M., Ataie, Z., Unutmaz, D. \& Ozbolat, I. T. 3D bioprinting for reconstituting the cancer microenvironment. NPJ Precis. Oncol. 4, 1-13 (2020).

35. Catros, S. et al. Layer-by-layer tissue microfabrication supports cell proliferation in vitro and in vivo. Tissue Eng. Part C. Methods. 18, 62-70 (2012).

36. Cidonio, G., Glinka, M., Dawson, J. I. \& Oreffo, R. O. C. The cell in the ink: Improving biofabrication by printing stem cells for skeletal regenerative medicine. Biomaterials 209, 10-24 (2019).

37. Nikolova, M. P. \& Chavali, M. S. Recent advances in biomaterials for 3D scaffolds: A review. Bioact. Mater. 4, 271-292 (2019).

38. Abdulghani, S. \& Morouço, P. G. Biofabrication for osteochondral tissue regeneration: Bioink printability requirements. J. Mater. Sci. Mater. Med. 30, 20. https://doi.org/10.1007/s10856-019-6218-x (2019).

39. Jafarkhani, M., Salehi, Z., Aidun, A. \& Shokrgozar, M. A. Bioprinting in vascularization strategies. Iran. Biomed. J. 23, 9-20 (2019).

40. Ma, X. et al. 3D bioprinting of functional tissue models for personalized drug screening and in vitro disease modeling. Adv. Drug Deliv. Rev. 132, 235-251 (2018).

41. Munaz, A. et al. Three-dimensional printing of biological matters. J. Sci. Adv. Mater. Devices. 1, 1-17 (2016).

42. Balachander, G. M., Balaji, S. A., Rangarajan, A. \& Chatterjee, K. Enhanced metastatic potential in a 3D tissue scaffold toward a comprehensive in vitro model for breast cancer metastasis. ACS Appl. Mater. Interfaces. 7, 27810-27822 (2015).

43. Neves, L. S., Rodrigues, M. T., Reis, R. L. \& Gomes, M. E. Current approaches and future perspectives on strategies for the development of personalized tissue engineering therapies. Exp. Rev. Precis. Med. Drug Dev. 1, 93-108 (2016).

44. Kim, B. S., Kim, H., Gao, G., Jang, J. \& Cho, D.-W. Decellularized extracellular matrix: A step towards the next generation source for bioink manufacturing. Biofabrication. 9, 034104. https://doi.org/10.1088/1758-5090/aa7e98 (2017).

45. Panwar, A. \& Tan, L. Current status of bioinks for micro-extrusion-based 3D bioprinting. Molecules 21, 685. https://doi.org/10.3390/ molecules21060685 (2016)

46. Niu, X., Wang, Y., Luo, Y., Xin, J. \& Li, Y. Arg-Gly-Asp (RGD) modified biomimetic polymeric materials. J. Mater. Sci. Technol. 21, 571-576 (2005).

47. Ruoslahti, E. RGD and other recognition sequences for integrins. Annu. Rev. Cell Dev. Biol. 12, 697-715 (1996).

48. Mandrycky, C., Wang, Z., Kim, K. \& Kim, D.-H. 3D bioprinting for engineering complex tissues. Biotechnol. Adv. 34, 422-434 (2016).

49. Chung, J. H. et al. Bio-ink properties and printability for extrusion printing living cells. Biomater. Sci. 1, 763-773 (2013).

50. Jia, J. et al. Engineering alginate as bioink for bioprinting. Acta Biomater. 10, 4323-4331 (2014).

51. Paxton, N. et al. Proposal to assess printability of bioinks for extrusion-based bioprinting and evaluation of rheological properties governing bioprintability. Biofabrication. 9, 044107. https://doi.org/10.1088/1758-5090/aa8dd8 (2017).

52. Ding, H. \& Chang, R. Printability study of bioprinted tubular structures using liquid hydrogel precursors in a support bath. Appl. Sci. 8, 403. https://doi.org/10.3390/app8030403 (2018).

53. Liu, W. et al. Extrusion bioprinting of shear-thinning gelatin methacryloyl bioinks. Adv. Healthc. Mater. 6, 1601451. https://doi. org/10.1002/adhm.201601451 (2017).

54. Jang, J. et al. Tailoring mechanical properties of decellularized extracellular matrix bioink by vitamin B2-induced photo-crosslinking. Acta Biomater. 33, 88-95 (2016).

55. Klotz, B. J., Gawlitta, D., Rosenberg, A. J., Malda, J. \& Melchels, F. P. Gelatin-methacryloyl hydrogels: Towards biofabrication-based tissue repair. Trends Biotechnol. 34, 394-407 (2016).

56. Jang, J., Park, J. Y., Gao, G. \& Cho, D. W. Biomaterials-based 3D cell printing for next-generation therapeutics and diagnostics. Biomaterials 156, 88-106 (2018).

57. Ma, X. et al. 3D bioprinting of functional tissue models for personalized drug screening and in vitro disease modeling. Adv. Drug Del. Rev. 132, 235-251 (2018).

58. Zhao, Y., Li, Y., Mao, S., Sun, W. \& Yao, R. The influence of printing parameters on cell survival rate and printability in microextrusion-based 3D cell printing technology. Biofabrication. 7, 045002. https://doi.org/10.1088/1758-5090/7/4/045002 (2015).

59. Giuseppe, M. D. et al. Mechanical behaviour of alginate-gelatin hydrogels for 3D bioprinting. J. Mech. Behav. Biomed. Mater. 79, 150-157 (2018).

60. Townsend, J. M., Beck, E. C., Gehrke, S. H., Berkland, C. J. \& Detamore, M. S. Flow behavior prior to crosslinking: The need for precursor rheology for placement of hydrogels in medical applications and for 3D bioprinting. Prog. Polym. Sci. 91, 126-140 (2019).

61. Wilson, S. A., Cross, L. M., Peak, C. W. \& Gaharwar, A. K. Shear-thinning and thermo-reversible nanoengineered inks for 3D bioprinting. ACS Appl. Mater. Interfaces. 9, 43449-43458 (2017).

62. Mondal, A. et al. Characterization and printability of sodium alginate-gelatin hydrogel for bioprinting NSCLC co-culture. Sci. Rep. 9, 1-12 (2019).

63. Zhao, G., Dai, C., Chen, A., Yan, Z. \& Zhao, M. Experimental study and application of gels formed by nonionic polyacrylamide and phenolic resin for in-depth profile control. J. Pet. Sci. Eng. 135, 552-560 (2015).

64. Naghieh, S., Karamooz-Ravari, M. R., Sarker, M., Karki, E. \& Chen, X. Influence of crosslinking on the mechanical behavior of 3D printed alginate scaffolds: Experimental and numerical approaches. J. Mech. Behav. Biomed. Mater. 80, 111-118 (2018).

65. Shim, J.-H., Kim, J. Y., Park, M., Park, J. \& Cho, D.-W. Development of a hybrid scaffold with synthetic biomaterials and hydrogel using solid freeform fabrication technology. Biofabrication. 3, 034102. https://doi.org/10.1088/1758-5082/3/3/034102 (2011).

66. Markstedt, K. et al. 3D bioprinting human chondrocytes with nanocellulose-alginate bioink for cartilage tissue engineering applications. Biomacromol 16, 1489-1496 (2015).

67. Yuan, H., Xing, K. \& Hsu, H. Y. Trinity of three-dimensional (3D) scaffold, vibration, and 3D printing on cell culture application: A systematic review and indicating future direction. Bioengineering (Basel). 5, 57. https://doi.org/10.3390/bioengineering503005 7 (2018).

68. Sun, M. et al. Effects of matrix stiffness on the morphology, adhesion, proliferation and osteogenic differentiation of mesenchymal stem cells. Int. J. Med. Sci. 15, 257-268 (2018).

69. Engler, A. et al. Substrate compliance versus ligand density in cell on gel responses. Biophys. J. 86, 617-628 (2004).

70. Cavo, M. et al. Microenvironment complexity and matrix stiffness regulate breast cancer cell activity in a $3 \mathrm{D}$ in vitro model. Sci. Rep. 6, 35367. https://doi.org/10.1038/srep35367 (2016). 
71. Sodupe Ortega, E., Sanz-Garcia, A. \& Escobedo-Lucea, C. Efficient fabrication of polycaprolactone scaffolds for printing hybrid tissue-engineered constructs. Materials. 12, 613. https://doi.org/10.3390/ma12040613 (2019).

72. Ribeiro, A. et al. Assessing bioink shape fidelity to aid material development in 3D bioprinting. Biofabrication. 10, 014102. https ://doi.org/10.1088/1758-5090/aa90e2 (2017).

73. Gorguluarslan, R. M., Gandhi, U. N., Mandapati, R. \& Choi, S.-K. Design and fabrication of periodic lattice-based cellular structures. Comput. Aided Des. Appl. 13, 50-62 (2016).

74. Giannitelli, S. M., Accoto, D., Trombetta, M. \& Rainer, A. Current trends in the design of scaffolds for computer-aided tissue engineering. Acta Biomater. 10, 580-594 (2014).

75. Sun, W., Starly, B., Darling, A. \& Gomez, C. Computer-aided tissue engineering: application to biomimetic modelling and design of tissue scaffolds. Biotechnol. Appl. Biochem. 39, 49-58 (2004).

76. Souness, A., Zamboni, F., Walker, G. M. \& Collins, M. N. Influence of scaffold design on 3 D printed cell constructs. J. Biomed. Mater. Res. Part B. Appl. Biomater. 106, 533-545 (2018).

77. Sun, M.-H. et al. Applications of hierarchically structured porous materials from energy storage and conversion, catalysis, photocatalysis, adsorption, separation, and sensing to biomedicine. Chem. Soc. Rev. 45, 3479-3563 (2016).

78. Nunes, A. S., Barros, A. S., Costa, E. C., Moreira, A. F. \& Correia, I. J. 3D tumor spheroids as in vitro models to mimic in vivo human solid tumors resistance to therapeutic drugs. Biotechnol. Bioeng. 116, 206-226 (2019).

79. Breslin, S. \& O’Driscoll, L. The relevance of using 3D cell cultures, in addition to 2D monolayer cultures, when evaluating breast cancer drug sensitivity and resistance. Oncotarget. 7, 45745-45756 (2016).

80. Douple, E. B. et al. Evaluation of drug efficacy in vitro using human small cell carcinoma of the lung spheroids. Cancer 56, 1918-1925 (1985).

81. Huh, D., Hamilton, G. A. \& Ingber, D. E. From 3D cell culture to organs-on-chips. Trends Cell Biol. 21, 745-754 (2011)

82. Weigelt, B., Ghajar, C. M. \& Bissell, M. J. The need for complex 3D culture models to unravel novel pathways and identify accurate biomarkers in breast cancer. Adv. Drug Del. Rev. 69, 42-51 (2014).

83. Bielecka, Z. F., Maliszewska-Olejniczak, K., Safir, I. J., Szczylik, C. \& Czarnecka, A. M. Three-dimensional cell culture model utilization in cancer stem cell research. Biol. Rev. Camb. Philos. Soc. 92, 1505-1520 (2017).

84. Kaushik, V., Yakisich, J. S., Kulkarni, Y., Azad, N. \& Iyer, A. K. V. Chemoresistance of lung cancer cells: 2D and 3D in vitro models for anticancer drug screening. Lung Cancer. Strateg. Diagn. Treat. https://doi.org/10.5772/intechopen.78946 (2018).

85. Kerr, D. J., Wheldon, T. E., Hydns, S. \& Kaye, S. B. Cytotoxic drug penetration studies in multicellular tumour spheroids. Xenobiotica 18, 641-648 (1988).

86. Gupta, S. K., Guzmán, E. A. T. \& Meenach, S. A. Coadministration of a tumor-penetrating peptide improves the therapeutic efficacy of paclitaxel in a novel air-grown lung cancer 3D spheroid model. Int. J. Cancer. 141, 2143-2153 (2017).

87. Adcock, A. F., Trivedi, G., Edmondson, R., Spearman, C. \& Yang, L. Three-Dimensional (3D) cell cultures in cell-based assays for in-vitro evaluation of anticancer drugs. J. Anal. Bioanal Tech. 6, 1. https://doi.org/10.4172/2155-9872.1000249 (2015).

88. Karlsson, H., Fryknäs, M., Larsson, R. \& Nygren, P. Loss of cancer drug activity in colon cancer HCT-116 cells during spheroid formation in a new 3-D spheroid cell culture system. Exp. Cell Res. 318, 1577-1585 (2012).

89. Mitchison, T. J. The proliferation rate paradox in antimitotic chemotherapy. Mol. Biol. Cell. 23, 1-6 (2012).

90. Lovitt, C. J., Shelper, T. B. \& Avery, V. M. Doxorubicin resistance in breast cancer cells is mediated by extracellular matrix proteins. BMC Cancer. 18, 41. https://doi.org/10.1186/s12885-017-3953-6 (2018).

91. Godugu, C. et al. AlgiMatrix ${ }^{\mathrm{TM}}$ based 3D cell culture system as an in-vitro tumor model for anticancer studies. PLoS ONE 8, e53708. https://doi.org/10.1371/journal.pone.0053708 (2013).

92. Baek, N., Seo, O. W., Kim, M., Hulme, J. \& An, S. S. A. Monitoring the effects of doxorubicin on 3D-spheroid tumor cells in realtime. Onco Targets Ther. 9, 7207-7218 (2016).

93. Mishra, A., Mukhopadhyay, S. K. \& Dey, S. Evaluation of cyclosaplin efficacy using a silk based 3D tumor model. Biomolecules. 9, 123. https://doi.org/10.3390/biom9040123 (2019).

94. Pickl, M. \& Ries, C. Comparison of 3D and 2D tumor models reveals enhanced HER2 activation in 3D associated with an increased response to trastuzumab. Oncogene 28, 461-468 (2009).

\section{Acknowledgements}

This project was supported by NSF-CREST center for Complex Material Design and also for Multidimensional Additive processing (CoMand) award \#1735968. The project was also supported by 'The Research Centers in Minority Institutions (RCMI) program' \#5U54MD0075007582-35 and Department of Veterans Affairs Merit Review Grant (BX00164).

\section{Author contributions}

A.G., S.K.S., J.H., and M.S. designed experiments and wrote the manuscript. A.G., S.K.S., A.M., A.B., P.A., S.K., N.P. and A.R. performed printing and cell-based assays. J.H., V.Z.W. and N.F.H. formulated hydrogels and performed rheology experiments. All authors reviewed the manuscript.

\section{Competing interests}

The authors declare no competing interests.

\section{Additional information}

Supplementary Information The online version contains supplementary material available at https://doi. org/10.1038/s41598-020-79325-8.

Correspondence and requests for materials should be addressed to M.S.

Reprints and permissions information is available at www.nature.com/reprints.

Publisher's note Springer Nature remains neutral with regard to jurisdictional claims in published maps and institutional affiliations. 
(c) (i) Open Access This article is licensed under a Creative Commons Attribution 4.0 International cc) License, which permits use, sharing, adaptation, distribution and reproduction in any medium or format, as long as you give appropriate credit to the original author(s) and the source, provide a link to the Creative Commons licence, and indicate if changes were made. The images or other third party material in this article are included in the article's Creative Commons licence, unless indicated otherwise in a credit line to the material. If material is not included in the article's Creative Commons licence and your intended use is not permitted by statutory regulation or exceeds the permitted use, you will need to obtain permission directly from the copyright holder. To view a copy of this licence, visit http://creativecommons.org/licenses/by/4.0/.

(C) The Author(s) 2021 